\title{
Video-feedback intervention in mother-baby dyads with depressive symptomatology and relationship difficulties
}

\author{
Marcia Olhaberry $^{1 凶}$, María José León ${ }^{2}$, Magdalena Seguel $^{1}$, \& Constanza Mena $^{1}$
}

\begin{abstract}
Post-partum depression (PPD) is one of the most common complications associated to maternal suffering, negative effects for the baby, and difficulties in the relationship. Video-feedback is a particularly effective technique used in dyadic early interventions. A brief intervention for mother-infant dyads with maternal depressive symptomatology was implemented using this technique, and was assessed in a longitudinal, quasi-experimental and quantitative study. 61 mother-baby dyads participated, with ages ranged from 18 to 41 years in mothers, and 8,4 to 18,8 months in their babies. The results show an improvement in the quality of the interaction, with a significant increase of maternal sensitivity, and a significant decrease in control. A significant reduction of depressive symptomatology was not found, although the frequency of major depression episodes and bonding risk decreased.
\end{abstract}

Keywords: early intervention, video-feedback, depression, maternal sensitivity

Human beings are born before attaining neurological maturity, which means that a large part of brain development must occur during the first years of life (Greenspan \& Benderly, 1998). For this reason, the post-partum environment and the early interpersonal experiences between a child and his/her main caregivers will influence the structural and functional evolution of his/her brain, his/her development, and his/her future mental health (Storfer, 1999; Schore, 2000; Mendes \& Seidl-de-Moura, 2014).

Upon the basis of microanalytic studies of mother-baby interactions, child development theories have shifted from considering that the mother unilaterally molds the child to propounding mutual influence (Stern, 1985). This has led current studies to regard the primary caregiver-child dyad as their unit of study. In this regard, there is consensus among researchers that the verbal and non-verbal communication process in the dyad contributes to the development of reciprocity, the exchange of in-

\footnotetext{
${ }^{1}$ Escuela de Psicología, Pontificia Universidad Católica de Chile.

${ }^{2}$ Universidad de Chile.

Correspondig Author: Marcia Olhaberry, Escuela de Psicología, Pontificia Universidad Católica de Chile; email to: mpolhabe@uc.cl
}

formation and feelings between both participants, and the quality of their bond (Trevarthen \& Aitken, 2001). Thus, the caregiver's interactive skills are associated with the child's expression of affection and type of response, especially during the first years of life (Kivijarvi, Voeten, Niemela, Raiha, Lertola, \& Piha, 2001).

Maternal mental health problems have been identified as a highly relevant factor in early mother-baby relationships and bonding quality, with postpartum depression (PPD) being one of the most common complications associated with maternal distress, negative effects for the baby, and relationship and bonding difficulties (O'Hara \& McCabe, 2013).

PPD shares characteristics with depression at other stages of the life cycle, with symptoms such as tiredness and feelings of loneliness and guilt (LeahyWarren \& McCarthy, 2007), as well as irritability, low spirits, emotional instability, anxiety, and sleeping disorders (American Psychiatric Association, 2013), with the latter often being regarded as part of the normal experience during this period (Halbreich \& Karkun, 2006).

In general terms, international studies show that between $6 \%$ and $38 \%$ of women suffer from depression during or after pregnancy (Field, 2011), with PPD prevalence ranging from $13 \%$ to $19 \%$ (O'Hara 
$\&$ McCabe, 2013). These figures are higher in developing countries (Evans, Vicuña, \& Marín, 2003): PPD surpasses $20 \%$ according to some studies conducted in Latin American communities (Moreno Zaconeta, Domingues Casulari da Motta, \& França, 2004; Urdaneta, Rivera, García, Guerra, Baabel, \& Contreras, 2010).

In Chile, a third of women display symptoms of depression and/or anxiety during pregnancy, while the prevalence of postpartum depression exceeds $40 \%$ (Jadresic, 2010). Studies show that the number of women with PPD increases over time; that is, while $10 \%$ are diagnosed after 8 weeks of postpartum, $22 \%$ receive this diagnosis 12 months after their baby is born (Barlow, McMillan, Kirkpatrick, Ghate, Barnes \& Smith, 2010), which stresses the need to provide support and monitoring during the first years of the baby's life.

Regarding the consequences of PPD for children, several negative effects have been described which impact their cognitive, emotional, and behavioral development, as well as the mother-child relationship (Field, 2011). Research shows that the babies of depressive mothers cry more often, are difficult to calm down, display more negative emotions, and avoid visual contact with the mother (Radesky, Zuckerman, Silverstein, Rivara, Barr, Taylor, Lengua \& Barr, 2013). At the psychological level, studies note that retarded development, mental health problems, cognitive deficits in pre-school and elementary school, and behavioral problems are more frequently present in the children of depressed mothers than in those of non-depressed ones (Podestá, Alarcón, Muñoz, Legüe, Bustos, \& Barría, 2013). In this context, the children of depressive mothers are at a higher risk of developing psychopathologies and particularly mood disorders (Pawlby, Hay, Sharp, Waters, \& O'Keane, 2009).

With respect to the mother-baby relationship, a number of flaws have been described in the parenting abilities of mothers with PPD, such as low sensitivity, lack of enjoyment, intrusive behaviors, negative emotions, and punitive behaviors during the interaction, as well as high stress and negative perceptions of their babies' behavior (Wan \& Green 2009). Likewise, depressed mothers have been observed to have low confidence in themselves and in their role (Zietlow, Schlüter, Nonnenmacher, Müller, \& Reck, 2014). Based on the difficulties of depressive mothers to display sensitive behaviors and positive and synchronic affects with their babies, perinatal maternal depression has also been associated with insecure child attachment (Hayes, Goodman, \& Carlson, 2013) and with greater negative effects on the bond depending on the severity and chronicity of the mother's depression (McMahon, Barnett, Kowalenko, \& Tennant, 2006).

Multiple studies show that early interventions, in general, foster adequate child development and increase caring behaviors and sensitive response from mothers towards their children (BakermansKranenburg, Van IJzendoorn, \& Juffer, 2003). However, in the case of PPD, most psychological interventions focus on reducing the mother's depression, with only a few attempting to simultaneously modify maternal depression and bonding quality (Milgrom, Schembri, Ericksen, Ross, \& Gemmill, 2011; Olhaberry, Escobar, San Cristobal, Santelices, Farkas, Rojas, \&Martínez, 2013). Studies reveal that the treatment of maternal depression does not necessarily entail improvements in the mother-baby relationship (Cooper \& Murray, 1995); thus, psychotherapeutic interventions that fulfill the mother's mental health needs have not always been shown to efficiently improve the baby's results, nor have they been observed to generate positive changes in child attachment (Murray, Cooper, Wilson, \& Romaniuk, 2003).

\section{Video Feedback Psychotherapeutic Interventions}

Video feedback is an especially effective technique used in early interventions. It has been applied to pursue a number of therapeutic objectives, either by itself or combined with other techniques (Kalinauskiene, Cekuoliene, Van IJzendoorn, BakermansKranenburg, Juffer, \& Kusakovskaja, 2009). These interventions comprise 3 to 4 video recording sessions of the mother and the baby playing together for 15 to 20 minutes (Rusconi-Serpa, Rossignol, \& McDonough, 2009). Afterwards, the recorded scenes are analyzed and certain sequences are selected to work with the adult, generally the mother.

This technique can reveal details of the motherbaby interaction which are usually undetectable while they happen due to their complexity and speed. Analyzing the interaction with the parents makes it possible to focus on specific aspects, which provides an opportunity to process and reflect on successful and difficult moments of the interaction (Fonagy, Gergely, Jurist, \& Target, 2002). This allows parents to observe themselves, identify emotions, and reorganize their mental representations of themselves and the baby (Beebe, 2003). Thus, with the therapist's help, these images are shown to the mother in order to foster her reflection on her baby's physical and verbal cues, as well as on her own representational models and bonding experiences (Rusconi-Serpa, Sancho Rossignol \& McDonough, 2009). According to Beebe (2014), video feedback allows parents to learn about their babies' non-verbal language, thus promoting new forms of interaction. The objective is to provide parents with a new perspective on the child's non-verbal language and his/her skills and behaviors (Beebe, 2010).

Video feedback interventions have been implemented and evaluated in a variety of specialized programs for outpatients in several cultures (Marvin, Cooper, Hoffman, \& Powell, 2002; Yagmur, Mesman, Malda, Bakermans-Kranenburg, \& Ekmekci, 2014). 
Studies reveal that these interventions significantly improve the sensitive response of mothers towards their babies and increase their feelings of self-efficacy associated with childrearing (Kalinauskien et al., 2009; Yagmur et al., 2014). On the other hand, these interventions have been observed to successfully reduce maternal symptomatology in hospital settings (Bilszta, Buist, Wang, \& Zulkefli, 2012), as well as in the home, improving the quality of child attachment and of the mother-child relationship (Van Doesum, RiksenWaraven, Hosman, Hoefnagels, 2008).

Other studies stress the contribution of video feedback in strengthening the mother's observation skills, increasing empathy and sensitivity to the baby's needs, and reinforcing the positive childrearing behaviors observed in the video (Van Zeijl, Mesman, Van IJzendoorn, Bakermans-Kranenburg, Juffer, Stolk \& Alink, 2006). In this context, some studies ascribe the positive results of video feedback interventions to their contribution to parental self-esteem and self-efficacy, which has a positive impact on the quality of parents' interaction with their children. Some of the factors found to be associated with these changes are: considering the reason for requesting professional help and integrating it in the intervention, having a positive experience during the first recording, focusing on positive aspects, promoting reflexive skills to understand one's emotional and mental states as well as the baby's, and creating a new way of understanding the dyad through reflection and conversation with the therapist (Doria, Kennedy, Strathie \& Strathie, 2013).

In the specific case of PPD, evidence indicates that after a video feedback intervention, mothers discover a more positive image of themselves and increase their enjoyment of the time they spend with their children, which has a positive impact on their bond (Vik \& Braten, 2009).In Chile, this technique has been applied in vulnerable families, and has been shown to improve maternal sensitivity (Suárez, Muñoz, Gómez, \& Santelices, 2009); however, it has not been specifically applied in dyads with mothers displaying depressive symptomatology.

Considering the information presented and the importance of early interventions in at-risk groups, we developed a brief video feedback intervention for mother-child dyads with maternal depressive symptomatology. We expected the intervened dyads to improve their interaction quality after the intervention, in terms of an increase in maternal sensitivity levels and a reduction in bonding risk and depressive symptomatology.

\section{Method}

\section{Design}

A longitudinal, quasi experimental study was conducted to evaluate the differences between the preand post-intervention measurements in the experimental and control groups. The interventions and evaluations were carried out during 2013 and 2014.

\section{Participants}

The participants in the present study were part of an intervention program for the promotion of maternal sensitivity and the reduction of depressive symptomatology that started in 2012 and ended on 2014. The participants belonged to a low or middlelow socioeconomic status and received healthcare in 5 public health centers located in peripheral areas of Santiago, Chile. The inclusion criteria considered for the study were: the presence of one or more risk factor for depression, depressive symptomatology (BDI score $\geq 5$ ), at least 18 years old, a pregnancy compatible with the life of the mother and the baby, and absence of severe physical psychopathology, addictions and/or psychosis. The pregnant women agreed to participate voluntarily in the study, previously signing a letter of informed consent in accordance with the ethical requirements in force in Chile.

The program included 4 measurements and 3 interventions, which considered different moments and modalities. Initially, 134 pregnant women were included into the program, 49 received the workshop for pregnant women and 85 were part of the control group. After the birth, 83 dyads continued to participate, 49 received a second group workshop and 31 continued in the control group. Finally, 61 dyads remained in the program, 30 received the video feedback intervention and 31 continued in the control group.

The first intervention consisted in 5 group sessions and was conducted during pregnancy in groups of approximately 8 women. The second consisted in 4 sessions directed to mother-infant dyads with approximately 4 dyads per group; and the third consisted in 4 individual video-feedback sessions (see flow chart in Figure 1).

For the research reported in this manuscript, 61 mother-child dyads were studied, all of them with maternal depressive symptomatology and receiving the usual treatment in public health centers in Santiago de Chile (brief individual psychotherapy and/or pharmacological therapy). 30 dyads were part of the experimental group and received the usual intervention provided by the health center alongside a video-feedback one. 31 dyads comprised the control group and only received the usual treatment provided by public health centers. The dyads were not randomly assigned to the groups, as due to ethical reasons at the beginning of the program all women were invited to participate in the group interventions while these were conducted. Once the interventions concluded, the contacted dyads that met the inclusion criteria were integrated to the control group. Dyads from the experimental group were included in an intervention program aimed at reducing depression and promoting 
a secure mother-baby bond, which included two group workshops and the video feedback intervention, which is analyzed in the present study. The dyads from the control group did not receive any of these interventions.

\section{STUDY FLOW CHART}

Inital enrolment: 134 pregnant women

( $\mathrm{BD} \geq 5$ risk factors for depression)

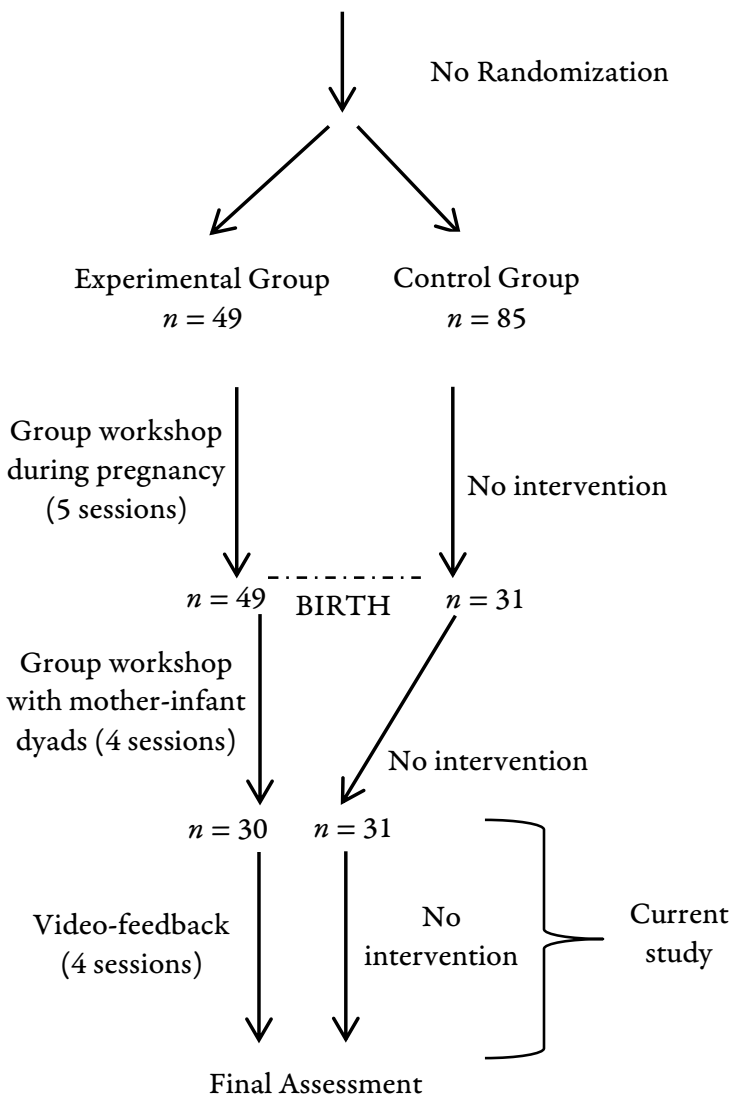

Figure 1. Flow chart

\section{Instruments}

The pre- and post-video feedback intervention measurements were conducted using the following instruments:

Personal information form: used to collect the participants' sociodemographic information and mental health history.

Beck Depression Inventory, BDI (Beck, Ward, Mendelson, Mock \& Erbaugh, 1961). This is a selfreporting questionnaire which is composed of 21 items. It evaluates current depressive symptoms. In this test, the subject must choose the phrase that best describes their emotional state over the previous week from a set of four alternatives ordered from lower to higher severity. Each item may be evaluated from 0 to 3 points, with a total score varying from 0 to 63 . Higher scores indicate greater depressive symptoms, and four categories of depres- sion are identified: minimum, 0-9; mild, 10-18; moderate, 19-29; and severe, 30-63. The reliability analysis is adequate, having been obtained from the Spanish version applied to patients with psychological disorders with an alpha value $=0.90$ (Vázquez \& Sanz, 1999).

Diagnostic Classification of Mental Health and Developmental Disorders of Infancy and Early Childhood, Zero to Three, DC: 0 - 3R (Link Egger, H., Fenichel, E., Guedeney, A., Wise, B $\&$ Wright, H., 2005). Mothers were asked to respond if the criteria for a depressive disorder in infancy was present or absent in their babies. When fulfilling all characteristics, depression was assessed. The instrument was incorporated to include an assessment of depression in the infant, considering the relevance of this variable not only in the mother as well in the child.

Mini-international neuropsychiatric interview (Sheehan, Lecrubier, Harnett-Sheehan, Janavs, Weiller, Bonara, Keskiner, Schinka, Knapp, Sheehan \& Dunbar, 1997). Explores 17 mental disorders defined in the DSM-IV-R, focusing on the patient's current symptomatology. In our study, the mood disorders module was used in order to obtain a clinical diagnosis of current major depression and to detect suicide risk and its level (mild, moderate, or high).

CARE-Index, Experimental Index of ChildAdult Relationships (Crittenden, 2006). Considers a 3- to 5-minute video recording of play interaction between the child and the adult. The coding system defines three descriptors for the adult: sensitive, controlling, and non-responsive, and four for the infant: cooperative, difficult, compulsive, and passive. It considers a dyadic sensitivity scale that ranges from 0 to 14 points, with 0-4 signaling "risk", 5-6 "inept", 7-10 "adequate", and 11-14 "sensitive"; scores below 7 indicate need for intervention. The video coding was conducted by psychologists trained by the author of the instrument, and reached a reliability of $\geq 0.7$ in the various scales used. The videos' codification was made without the presence of information regarding the source of the videos, neither the belonging to the experimental nor control group. The inter-judge reliability between the 3 codifiers that participated in the study was 0.72 , which is considered adequate by the author of the instrument.

The instrument was included to assess the quality of mother-infant interactions considering its utility and clinical richness, the use of observational material and the existence in Chile of codifiers certificated by the author.

\section{Procedure}

The women were first contacted during pregnancy and invited to participate in the program. Then, after two interventions they were invited to partici- 
pate with their children in the video-feedback intervention through the health centers that they attended. A scale was applied to evaluate their depressive symptomatology (BDI); those who obtained 5 or more points and presented one or more of the risk factors usually identified during pregnancy in Chile (late involvement in prenatal care, low educational attainment, use or abuse of controlled substances, gender violence, maternal conflicts, insufficient social support, and depressive symptoms) were included in the program and asked to sign an informed consent letter. At this point, their sociodemographic data were collected. Then, a clinical diagnosis of mood disorders according to the DSM-IV R (MINI) was conducted. After their babies were born, videos were recorded to evaluate maternal sensitivity and the quality of the interaction through the CARE-Index. The mothers' depressive symptoms were measured again after the video-feedback intervention. All evaluations were conducted by psychologists and senior clinical psychology students, previously trained to apply each of the instruments. The study was carried out simultaneously with the psychological and/or psychiatric treatments provided by the health center. The information associated with these treatments was included in the study and its variables were controlled when performing the statistical analyses.

We took into account the intervention in guided interactions developed by McDonough (1993, 2004) and the ODISEA model developed in Chile by Gómez and Muñoz (2013) to generate a 4session adaptation. The intervention was adapted, considering the necessity of generating a procedure for depressive mothers and their infants, adjusted to their emotional necessities and feasible to implement in the mother's home in a low number of sessions. The considered models do not directly address depression; neither they are exclusively oriented to dyads with toddlers. It was implemented by five pairs of psychologists, formed in the model in a 30-hours training that included weekly clinical meetings to analyze and discuss the cases.

First Session: The mother's concerns over the child or the relationship are explored. Then, a 15 minute video is recorded of the mother-child play interaction with an age-appropriate set of toys, and finally the experience is discussed and a task connected with the experience is defined.

Post-session work: the two therapists identify the positive and negative sequences in the video, in order to link the interactions observed to the mother's concerns. Afterwards, they select segments from positive interactions, defining their therapeutic use and the focus of the intervention. In addition, they define questions to be asked to the mother while she watches the segments that refer to both participants' emotional experiences, internal states, needs, and relationship. The questions are intended to fos- ter the mother's recognition of the child's needs, her sensitive response, her mentalizing function, and her identification of mutual influence.

Second session (Feedback): The selected sequences are shown and the mother is prompted to reflect on these segments through questions about them; afterwards, a new task is co-constructed. The duration of this session is approximately 60 minutes.

Sessions 3 and 4 replicate the structure of the first 2 , but a video in which the mother feeds her child is added, in order to introduce an everyday activity that involves a higher level of stress than free play. Session 4 also includes an evaluation of the process. The sessions were conducted once a week, having completed the entire intervention in one month.

The main intervention techniques used during the video-feedback sessions with the mother were: speaking for the child, questions (about the observed, its relation with other interactions, about the child, about themselves), deliver information about the child's developmental stage, identification of sensitive interaction chains, reinforcement for the mother, exploration of inner states that underlies the conduct, reflection, build new meanings.

\section{Data analysis}

Before statistically analyzing the data, we evaluated the presence of atypical values and the fulfillment of the assumptions of the statistical tests conducted, specifically an assessment of the normality of the variables was conducted through the KolmogorovSmirnov $\mathrm{Z}$ test and QQ graphics were assessed for the analysis of atypical data. The significance criterion used was $\alpha=0.05$. We conducted a descriptive analysis of the variables studied in each group, their levels of association, and finally a pre- and postintervention comparison between the groups using a mixed ANOVA. Due to their possible effect on the results, the variables -assistance to psychological treatment-, and -assistance to pharmacological treatment- were controlled during the intervention, including them as co-variables.

\section{Results}

\section{Descriptive statistics}

The sociodemographic information collected indicates that the participants' mothers' mean age is $27.64(S D=6.19)$, and that it ranges from 18 to 41 . The participating children had a mean age of 13.9 months of age $(S D=2.59)$, with ranges between 8.4 and 18.8. No significant differences are observed between the groups in terms of the mothers' age $(p$ $>.05)$, years of education $(p>.05)$, or number of children $(p>.05)$. Also, no differences exist between the groups in terms of the proportion of women with a couple $(p>.05)$ or between the age and sex 
of the children in the two groups $(p>.05)$. Tables 1 and 2 detail the descriptive statistics of each group in the variables mentioned.

Table 1. Descriptive statistics of the participants' sociodemographic data

\begin{tabular}{lcccc}
\hline & $\begin{array}{c}\text { Control Group } \\
(n=31)\end{array}$ & \multicolumn{2}{c}{$\begin{array}{c}\text { Experimental } \\
\text { Group } \\
(n=30)\end{array}$} \\
Variable & $M$ & $S D$ & $M$ & $S D$ \\
\hline Mother's age (years) & 28.23 & 6.184 & 27.03 & 6.250 \\
Years of education & 11.74 & 2.352 & 11.87 & 2.488 \\
Child's age (months) & 13.28 & 2.720 & 14.620 & 2.290 \\
\hline
\end{tabular}

Table 2. Frequencies and percentages of the participants sociodemographic data

\begin{tabular}{lcccc}
\hline & $\begin{array}{c}\text { Control Group } \\
(n=31)\end{array}$ & \multicolumn{3}{c}{$\begin{array}{c}\text { Experimental } \\
\text { Group } \\
(n=30)\end{array}$} \\
Variable & Frequency & $\%$ & Frequency & $\%$ \\
\hline Has a couple & 30 & 96.8 & 23 & 76.7 \\
$\mathrm{~N}^{\circ}$ of children & & & & \\
1 & 8 & 25.8 & 13 & 43.3 \\
2 & 15 & 48.4 & 11 & 36.7 \\
$\geq 3$ & 8 & 25.9 & 6 & 20.0 \\
Female child & 15 & 48.4 & 12 & 40.0 \\
\hline
\end{tabular}

Tables 3 and 4 show the averages and standard deviations of the mothers' and the children's interaction descriptors and depressive symptomatology in the pre and post measurements, by group.

\section{Comparative analyses}

In order to determine the effectiveness of the video feedback intervention in the variables studied, analyses were applied to compare both groups using mixed ANOVA.

Regarding the effects of the intervention on the quality of the mother-baby interaction as measured through the CARE-Index, the results show an increase in maternal sensitivity over time in the experimental group dyads, with their postintervention score being statistically higher than that of the control group dyads in this variable (Wilks' $\lambda=0.739, F(1,59)=20.883 ; \mathrm{p}<.001)$. The power observed for this test was .99 and the effect size was $\eta_{p}^{2}=.261$ Figure 1 shows the variations in maternal sensitivity between the groups after receiving the intervention.

The results of the analysis of the other maternal behavior descriptors show significant inter-group differences in the controlling descriptor, with significantly higher scores in the non-intervened group (Wilks' $\lambda=0.863, F(1,59)=9.331 ; \mathrm{p}<.001)$. The power observed for this test was .85 and the effect size was $\eta_{p}{ }^{2}=.137$. The scores for maternal nonresponsiveness do not vary significantly over time or between groups (power $=.16$; effect size $\eta_{p}^{2}=.016$; $\mathrm{p}>.05$ ). Figure 2 shows the variations in controlling maternal behavior by group.

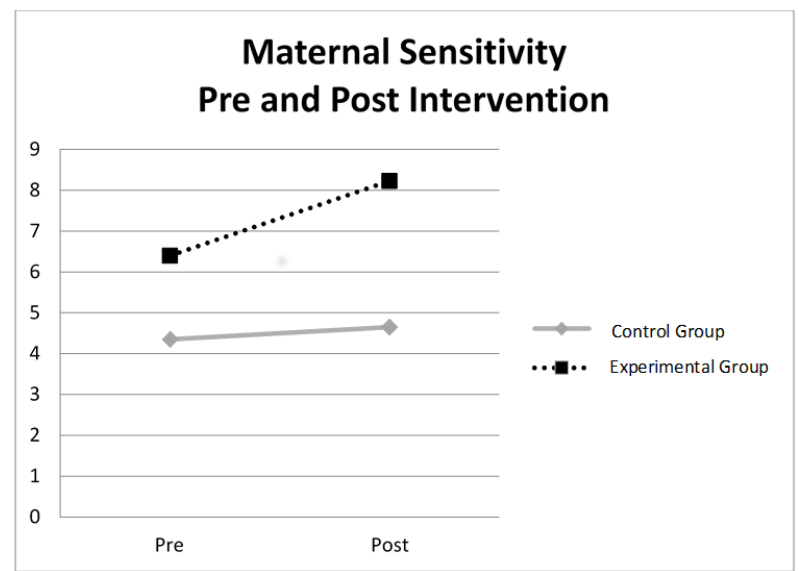

Figure 1: Evolution of maternal sensitivity in the control and experimental groups before and after the video feedback intervention. The power of the test was .994 .

Table 3. Descriptive statistics of the mother-infant interaction descriptors

\begin{tabular}{|c|c|c|c|c|}
\hline \multirow[b]{2}{*}{ Descriptor } & \multicolumn{2}{|c|}{$\begin{array}{l}\text { Control Group } \\
\quad(n=31)\end{array}$} & \multicolumn{2}{|c|}{$\begin{array}{l}\text { Experimental Group } \\
\qquad(n=30)\end{array}$} \\
\hline & $\begin{array}{c}\text { Pre } \\
M(S D)\end{array}$ & $\begin{array}{c}\text { Post } \\
M(S D)\end{array}$ & $\begin{array}{c}\text { Pre } \\
M(S D)\end{array}$ & $\begin{array}{c}\text { Post } \\
M(S D)\end{array}$ \\
\hline \multicolumn{5}{|l|}{ Mother } \\
\hline Sensitive & $4.35(1.01)$ & $4.65(0.83)$ & $6.40(1.90)$ & $8.23(1.79)$ \\
\hline Controlling & $4.87(3.13)$ & $5.55(3.13)$ & $4.30(2.52$ & $2.70(2.43)$ \\
\hline Non responsive & $4.84(3.30)$ & $3.84(3.36)$ & $3.33(2.77)$ & $3.07(2.16)$ \\
\hline \multicolumn{5}{|l|}{ Infant } \\
\hline Cooperative & $3.94(1.12)$ & $4.52(0.89)$ & $6.07(2.06)$ & $7.90(1.78)$ \\
\hline Difficult & $2.74(2.92)$ & $0.97(1.62)$ & $1.50(1.88)$ & $2.00(2.28)$ \\
\hline Compulsive & $3.19(2.89)$ & $5.16(2.59)$ & $2.23(2.23)$ & $1.77(1.94)$ \\
\hline Passive & $4.23(2.62)$ & $3.32(2.34)$ & $4.27(2.63)$ & $2.30(1.41)$ \\
\hline
\end{tabular}


Table 4. Averages and standard deviations of maternal depressive symptomatology (BDI) by group, and frequencies and percentages by depression diagnostic category.

\begin{tabular}{|c|c|c|c|c|}
\hline & \multicolumn{2}{|c|}{$\begin{array}{l}\text { Control Group } \\
\quad(n=31)\end{array}$} & \multicolumn{2}{|c|}{$\begin{array}{l}\text { Experimental Group } \\
\qquad(n=30)\end{array}$} \\
\hline & Pre & Post & Pre & Post \\
\hline & $M(S D)$ Freq $(\%)$ & $M(S D)$ Freq $(\%)$ & $M(S D)$ Freq $(\%)$ & $M(S D)$ Freq $(\%)$ \\
\hline Total BDI & $12.42(10.90)$ & $11.87(9.04)$ & $12.03(7.88)$ & $9.43(7.20)$ \\
\hline Minimum (0-9) & $3.4(2.4) 15(48.4)$ & $4.8(2.4) 16(51.6)$ & $4.92(3.2) 12(40)$ & $5.1(2.5) 19(63.3)$ \\
\hline Mild (10-18) & $14.5(2.9) \quad 9(29.0)$ & $14.3(2.7) \quad 8(25.8)$ & $13.2(2.6) 12(40)$ & $13.1(2.8) \quad 8(26.7)$ \\
\hline Moderate (19-29) & $24.5(5.2) \quad 4(12.9)$ & $21.6(1.1) \quad 5(16.1)$ & $20.5(1.9) 4(13.3)$ & $26.6(2.0) 3(10.0)$ \\
\hline Severe (30-63) & $34.6(2.8) \quad 3(9.7)$ & $34.0(2.8) \quad 2(6.5)$ & $30.5(0.7) \quad 2(6.7)$ & $0(0)$ \\
\hline
\end{tabular}

With respect to the quality of the interaction in the studied dyads, the results reveal smaller frequencies of bonding risk in the experimental group and a stronger need for subsequent intervention in the dyads that were not intervened using video feedback (see table 5).

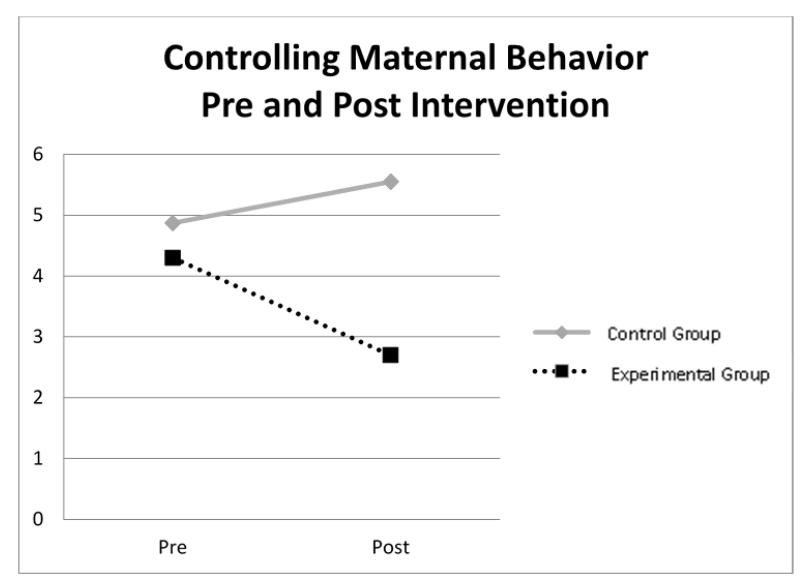

Figure 2. Evolution of maternal control in the experimental and control groups before and after the video feedback intervention. The power of the test was .852 .

Table 5. Frequencies (F) and percentages (\%) by group in the Sensitivity Scale categories (risk, inept, adequate, sensitive).

\begin{tabular}{lcccc}
\hline $\begin{array}{l}\text { Sensitivity } \\
\text { Scale }\end{array}$ & \multicolumn{2}{c}{$\begin{array}{c}\text { Control Group } \\
(n=31)\end{array}$} & \multicolumn{2}{c}{$\begin{array}{c}\text { Experimental Group } \\
(n=30)\end{array}$} \\
\hline & Pre & Post & Pre & Post \\
& Freq (\%) & Freq (\%) & Freq (\%) & Freq (\%) \\
Risk & $13(41.9)$ & $14(45,2)$ & $3(10.0)$ & 0 \\
Inept & $18(58.1)$ & $16(51.6)$ & $19(63.3)$ & $5(16.7)$ \\
Adequate & 0 & $1(3.2)$ & $5(16.7)$ & $19(63.3)$ \\
Sensitive & 0 & 0 & $3(10.0)$ & $6(20.0)$ \\
\hline
\end{tabular}

With respect to the quality of the interaction in the studied dyads, the results reveal smaller frequencies of bonding risk in the experimental group and a stronger need for subsequent intervention in the dyads that were not intervened using video feedback (see table 5).
The analyses conducted to determine the differences between the groups in maternal depressive symptomatology show a reduction in the average scores of both, but the differences are not statistically significant $\left(W_{i l k s}^{\prime} \lambda=0.982, F(1,58)=1.086\right.$; $p>.001)$. The power observed for this test was .17 and the effect size was $\left.\eta_{p}^{2}=.018\right)$. Even though the intervention was not observed to have an effect on the mothers' depressive symptoms, the major depression and childhood depression frequencies are lower in the intervened group, association that is statistically significant $\left(X^{2}{ }_{2}=8.099 ; p=.017\right)$. The frequencies of these variables in the pre and post measurements are presented in table 6 .

Table 6. Frequencies (F) and percentages (\%) of maternal major depression (MD) and childhood depression before and after the intervention, evaluated with the MINI and the DC:0-3R.

\begin{tabular}{lcccc}
\hline & \multicolumn{2}{c}{$\begin{array}{c}\text { Control Group } \\
n=31\end{array}$} & \multicolumn{2}{c}{$\begin{array}{c}\text { Experimental Group } \\
n=30\end{array}$} \\
\cline { 2 - 5 } & Pre & Post & Pre & Post \\
& Freq (\%) & Freq (\%) & Freq (\%) & Freq (\%) \\
$\begin{array}{l}\text { Maternal MD } \\
\begin{array}{c}\text { Childhood } \\
\text { depression }\end{array}\end{array}$ & $23(72.4)$ & $13(41.9)$ & $19(63.3)$ & $3(10.0)$ \\
\hline
\end{tabular}

\section{Discussion}

Studies focusing on early childhood have consistently shown the clinical relevance of early interventions in mother-infant dyads that experience difficulties in the establishment of the first bond (Schore, 2000), which emphasizes the need of conducting them when mothers are depressed or display high symptomatology (O'Hara, \& McCabe, 2013).

Consistently with the theoretical literature reviewed, the results of the intervention conducted confirm the effectiveness of early video feedback interventions in dyads with maternal depressive symptomatology and relationship difficulties. The results 
reveal a significant increase in maternal sensitivity and child cooperativeness in the intervened dyads, and in a qualitative level, along with lower frequencies of bonding risk, which reveals a positive effect on these variables and confirms one of our hypotheses. These results are especially relevant if we consider the positive association between adequate maternal sensitivity and the generation of a secure attachment pattern in the baby, as well as its link with positive emotional, cognitive, and social development (Coppola, Vaughn, Cassiba, \& Constantini, 2006).

A more specific analysis of the results in the area of mother-baby bond quality shows that the significant changes associated with the intervention are observed mostly in maternal sensitivity and controlling behavior, with the former increasing and the latter decreasing in the experimental group. That is, the mothers in the experimental group display an increased ability to read children's signals, interpret them adequately, and respond suitably and in accordance with their needs, alongside a decrease in their hostile behavior, in terms of overt or concealed anger, which can be manifested through incongruity in maternal behavior or direct intrusions. These results are consistent with previous studies, which report improved sensitivity and reduced intrusive behavior in mothers during their interactions with their babies (Kalinauskien et al., 2009; Yagmur et al., 2014). It is relevant to highlight that the mothers in the non intervened group display increased controlling behavior, associated with hostility, which warns us about this group's greater bonding risk and points to the clinical value of video feedback for the early prevention of child abuse. As previously noted (Kalinauskien et al., 2009; Yagmur et al., 2014), early interventions with video feedback foster maternal self-efficacy, which can provide mothers with more security and promote the use of regulatory mechanisms other than hostility. Likewise, the intervention made it possible for mothers to more clearly detect their babies' emotional needs, allowing them to provide more sensitive and assertive responses.

Despite the significance of the findings in relation to the increase of the maternal sensitivity in the intervened group, is important to highlight that the average scores obtained for this variable in the previous-to-intervention measure, are significantly higher for the mothers in the experimental group. The same is observed in the number of dyads that present a pre-intervention bonding risk, with a higher frequency for the control group than for the experimental group. These findings could be explained because of the positive effect of participating in the group workshops before the video/feedback intervention, even though the significant rise in sensitivity after the last measure, is only observed in the experimental group dyads, showing the control group sustained levels for maternal sen- sitivity and bonding risk frequency.

Regarding the non-responsive maternal behavior, the literacy describes in depressive mothers a tendency to become inward to their own inner states, showing themselves less available emotionally and psychologically toward their babies, and with difficulties to response to the infant signs, especially when are shown with a low threshold (Pawlby et al., 2009). In this matter, differences post-intervention were not found for this descriptor as it was expected, what could be explained because of the characteristics of the developmental stage of the children (average age 13,9 months), characterized for the increasing achievement of gross motor skills that allows a further autonomy and movement, which probably activates a controlling behavior in mothers when the sensitivity is affected. Further longitudinal studies assessing the variations in maternal behavior descriptors according to the stage of children's development are required, in order to confirm or denied this hypothesis.

When considering qualitatively the Sensitivity Scale results for both groups, dyads with bonding risk increase in the control group and disappear in the experimental group; in the latter, also, the number of dyads in the adequate and sensitive categories increases, which indicates a global improvement in the quality of mother-child exchanges.

With respect to maternal depressive symptomatology, no significant differences were observed between the groups, with both displaying minimal symptom reduction in the final measurement. Although the intervention was expected to contribute to reducing the mothers' symptoms, the results did not confirm this hypothesis. Nevertheless, qualitatively the higher frequency of major depression diagnoses in the mothers and children in the non intervened group point to the positive influence of the intervention on depression. It is also noteworthy that the number of children who meet the major depression criteria increases in the control group (from 5 to 13) even though the number of depressed mothers is reduced in it (from 23 to 13). Complementarily, the intervened group includes some mothers diagnosed with major depression in the final measurement ( 3 mothers), but none of them is within the risk category in the sensitivity scale, which may indicate that maternal sensitivity and depression are not necessarily associated. Some studies (NICHD Early Child Care Research Network, 1999; Maughan, Cicchetti, Toth \& Rogosch, 2007) have suggested that maternal sensitivity may be a factor that moderates the noxious impact of maternal depression on the baby's development. In this regard, the intervention conducted may be a useful tool for interrupting the transgenerational transmission of depression from mothers to their children. On the other hand, the differences found between the major depression diagnoses and the 
symptomatology measurements stress the need to include both elements, because screening instruments often give false positives and false negatives; therefore, more thorough diagnoses are needed for the early identification of the aspects that may hinder the construction of a positive mother-child bond.

Some researchers (Székely et al., 2014) have proposed that, in order to increase the benefits resulting from early interventions, it is necessary to consider both maternal sensitivity and depression. Even though the results of the present study do not reveal a significant reduction in depressive symptomatology, it was possible to establish that video feedback interventions are a useful tool to improve the quality of the mother-child bond, reduce the frequency of major depressive episodes, and, possibly, interrupt the transgenerational transmission of psychopathology from mothers to their children. In addition, it is important to hypothesize about the specific contribution of the use of video-feedback in the increase of maternal sensitivity, which could be explained by its favorable effect on parental self-esteem and self-efficacy and the positive impact of these variables in the quality of the mother-infant interactions (Doria, Kennedy, Strathie \& Strathie, 2013).

Nevertheless, these findings must be confirmed using larger samples, and also taking into account the father's influence on mother-infant interaction, along with other aspects of the mother's personality structure which may interfere with the results or require parallel interventions (dyadic and individual). The lack of follow-up evaluations in this study is a limitation that makes it impossible to test the permanence of the changes observed, and should be an aspect to be considered in future research. In addition, another limitation of this study is the quasi-experimental design utilized and the impossibility of distinguishes in a precise manner between the effect of the video feedback intervention and the effect of the previous group interventions. The existence of babies under the age of 12 months in the sample constitutes also a limitation, because most of the successful videofeedback intervention consider dyads with children above this age. These aspects must be taken into account when considering the reach of the results. Likewise, follow-up evaluations could look into potential reductions in maternal depressive symptomatology, because the positive effects of the intervention on the bond can provide a less stressful context, thus benefiting the mother's mood (Matthey, Kayanagh, Howie, Barnett \& Charles, 2004).

\section{Acknowledgments}

Authors' note: We are thankful for the support and funding provided by the National Committee for Scientific and Technological Research (CONICYT Chile), by Fondecyt Projects No3120109 and $\mathrm{N}^{\circ} 11140230$, and by the Innovation for Competi- tiveness Fund (FIC), part of the Ministry of Economy, Development, and Tourism, through the Millennium Scientific Initiative, Project IS130005. We also thank the team of clinical psychologists who participated in the implementation of the intervention: Marta Escobar, Johana Zapata, Ángela Miranda, Macarena Romero, Catalina Sieverson, Trinidad Illanes, Francisca Siles, Franchesca Aguirre, and Claudia Aldana.

\section{References}

American Psychiatric Association. (2013). Diagnostic and statistical manual of mental disorders (5th ed.). Washington, DC: Author.

Bakermans-Kranenburg, M. J., Van Ijzendoorn, M. H., \& Juffer, F. (2003). Less is more: meta-analyses of sensitivity and attachment interventions in early childhood. Psychological Bulletin, 129(2), 195. doi: 10.1037/0033-2909.129.2.195

Barlow, J., McMillan, A., Kirkpatrick, S., Ghate, D., Barnes, J., \& Smith, M. (2010). Health-let interventions in the early years to enhance infant and maternal mental health: A review of reviews. Child and Adolescent Mental Health, 15, 178-185. doi: 10.1111/j.1475-3588.2010.00570.x

Beebe, B. (2003). Brief mother-infant treatment using psychoanalytically informed video feedback. Infant Mental Health Journal, 24(1), 24-52. doi: 10.1002/imhj.10042

Beebe, B. (2010). Mother-Infant Research Informs Mother-Infant Treatment. Clinical Social Work Journal, 38(1), 17-36. doi: 10.1007/s10615-009-0256-7

Beebe, B. (2014). My Journey in Infant Research and Psychoanalysis: Microanalysis, a Social Microscope. Psychoanalytic Psychology, 31(1), 4-25. doi: 10.1037/a0035575

Bilszta, J. L., Buist, A. E., Wang, F., \& Zulkefli, N. R. (2012). Use of video feedback intervention in an inpatient perinatal psychiatric setting to improve maternal parenting. Archives of Women's Mental Health, 15(4), 249-257. doi: 10.1007/s00737-012-0283-1

Cooper, P. J., \& Murray, L. (1995). Course and recurrence of postnatal depression. Evidence for the specificity of the diagnostic concept. The British Journal of Psychiatry, 166(2), 191-195. doi: 10.1192/bjp.166.2.191

Coppola, G., Vaughn, B., Cassiba, R. \& Costantini, A. (2006). The attachment script Representation procedure in an Italian simple: Associations with Adult Attachment Interview scales and with maternal sensitivity. Attachment \& Human Development, 8(3): 209-219.

doi: 10.1080/14616730600856065

Doria, M. V., Kennedy, H., Strathie, C., \& Strathie, S. (2013). Explanations for the Success of Video Interaction Guidance (VIG): An Emerging Method in Family Psychotherapy. The Family Journal: Counseling and Therapy for Couples and Families, $O O(0), 1-10$. doi: 10.1177/1066480713505072

Evans, M., Vicuña, M., \& Marín, R. (2003). Depresión postparto realidad en el sistema público de atención de salud. Revista chilena de obstetricia y ginecología, 68(6), 491-494. doi: $10.4067 /$ S0717-75262003000600006

Field, T. (2011). Prenatal depression effects on development. Infant Behavior and Development, 34, 1-14. doi: 10.1016/j.infbeh.2010.09.008

Fonagy, P., Gergely, G., Jurist, E., \& Target, M. (2002). Affect regulation, mentalization, and the development of self. New York: Other Press.

Greenspan, S. \& Benderly, B. (1998). El crecimiento de la mente. Barcelona, Paidós.

Halbreich, U. \& Karkun, S. (2006). Cross-cultural and social diversity of prevalence of postpartum depression and de- 
pressive symptoms. Journal of Affective Disorders, 91, 97111. doi: 10.1016/j.jad.2005.12.051

Hayes, L. J., Goodman, S. H., \& Carlson, E. (2013). Maternal antenatal depression and infant disorganized attachment at 12 months. Attachment \& human development, 15(2), 133-153. doi: 10.1080/14616734.2013.743256

Jadresic, E. (2010). Depresión en el embarazo y el puerperio. Revista chilena de neuro-psiquiatría, 48(4), 269-278. doi: 10.4067/S0717-92272010000500003

Kalinauskiene, L., Cekuoliene, D., Van IJzendoorn, M. H., Bakermans-Kranenburg, M. J., Juffer, F., \& Kusakovskaja, I. (2009). Supporting insensitive mothers: the Vilnius randomized control trial of video-feedback intervention to promote maternal sensitivity and infant attachment security. Child: Care, Health and Development, 35(5), 613-623.

Kivijarvi M., Voeten M., Niemela P., Raiha H., Lertola K., Piha J. (2001). Maternal Sensitivity Behavior and Infant Behavior in Early Interaction. Infant Mental Health Journal, 22(6), 627-640. doi: 10.1002/imhj.1023

Leahy-Warren, P. \& McCarthy, G (2007) Postnatal depression: Prevalence, mothers' perspectives, and treatments. Archives of Psychiatric Nursing, 21(2): 91-100. doi: 10.1016/j.apnu. 2006.10.006

Marvin R, Cooper G, Hoffman K, Powell B (2002) The Circle of Security project: attachment-based intervention with caregiver-pre-school child dyads. Attachment $\mathrm{Hu}$ man Development, 4(1), 107-124. doi: 10.1080/14616730252982491

Matthey, S., Kavanagh, D., Howie, P., Barnett, B., y Charles, M. (2004). Prevention of postnatal distress or depression: An evaluation of an intervention at preparation for parenthood classes. Journal of Affective Disorders, 79, 113126. doi: 10.1016/S0165-0327(02)00362-2

Maughan, A., Cicchetti, D., Toth, S. \& Rogosch, F. (2007) Early-occurring Maternal Depression and Maternal Negativity in Predicting Young Children's Emotion Regulation and Socioemotional Difficulties. Journal of Abnormal Child Psychology, 35, 685-703. doi: 10.1007/s10802-007-9129

McMahon, C. A., Barnett, B., Kowalenko, N. M., \& Tennant, C. C. (2006). Maternal attachment state of mind moderates the impact of postnatal depression on infant attachment. Journal of Child Psychology and Psychiatry, 47(7), 660-669. doi: 10.1111/j.1469-7610.2005.01547.x

Mendes, D. M. L. F. \& Seidl-de-Moura, M. L. (2014). Different Kinds of Infants' Smiles in the First Six Months and Contingency to Maternal Affective Behavior. Spanish Journal of Psychology, 17 (e80), 1-12. doi: 10.1017/sjp.2014.86

Milgrom, J., Schembri, C., Ericksen, J., Ross, J., \& Gemmill, A. W. (2011). Towards parenthood: An antenatal intervention to reduce depression, anxiety and parenting difficulties. Journal of affective disorders, 130(3), 385-394. doi: 10.1016/j.jad.2010.10.045

Moreno Zaconeta, A., Domingues Casulari da Motta, L., \&França, P. S. (2004). Depresión postparto: prevalencia de test de rastreo positivo en puérperas del Hospital Universitário de Brasília, Brasil. Revista chilena de obstetricia $y$ ginecología, 69(3), 209-213.

Murray, L., Cooper, P. J., Wilson, A., \& Romaniuk, H. (2003). Controlled trial of the short-and long-term effect of psychological treatment of post-partum depression 2 . Impact on the mother-child relationship and child outcome. The British Journal of Psychiatry, 182(5), 420-427. doi: 10.1192/bjp.182.5.420

NICHD Early Child Care Research Network (1999). Chronicity of Maternal Depressive Symptoms, Maternal Sensitivity, and Child Functioning at 36 Months. Developmental Psychology, 35 (5), 1297-1310. doi: 10.1037/00121649.35.5.1297
O'Hara, M. W., \& McCabe, J. E. (2013). Postpartum depression: current status and future directions. Annual Review of Clinical Psychology, 9, 379-407. doi: 10.1146/annurevclinpsy-050212-185612

Olhaberry, M., Escobar, M., San Cristobal, P., Santelices, P., Farkas, Ch., Rojas, G., Martínez, V. (2013). Intervenciones psicológicas perinatales en depresión materna $\mathrm{y}$ vínculo madre-bebé: Una revisión sistemática. Terapia Psicológica, 31(2), 249-261. doi: 10.4067/S071848082013000200011

Pawlby, S., Hay, D., Sharp, D., Waters, C., \& O’Keane, V. (2009). Antenatal depression predicts depression in adolescent offspring: prospective longitudinal communitybased study. Journal of Affective Disorders, 113, 236-243. doi: $10.1016 /$ j.jad.2008.05.018

Podestá, L., Alarcón, A. M., Muñoz, S., Legüe, M., Bustos, L., \& Barría, M. (2013). Alteración del desarrollo psicomotor en hijos de mujeres con depresión posparto de la ciudad de Valdivia-Chile. Revista médica de Chile, 141(4), 464470. doi: 10.4067/S0034-98872013000400007

Radesky, J. S., Zuckerman, B., Silverstein, M., Rivara, F. P., Barr, M., Taylor, J. A., Lengua, L., \& Barr, R. G. (2013). Inconsolable infant crying and maternal postpartum depressive symptoms. Pediatrics, 131(6), e1857-e1864. doi: 10.1542/peds.2012-3316

Rusconi-Serpa, S., Sancho Rossignol, A., \& McDonough, S. C. (2009). Video feedback in parent-infant treatments. Child and Adolescent Psychiatric Clinics of North America, 18(3), 735-751. doi: 10.1016/j.chc.2009.02.009

Schore, A.N. (2000). Attachment and the regulation of the right brain. Attachment and Human Development, 2, 2347. doi: 10.1080/146167300361309

Sheehan, D. V., Lecrubier, Y., Harnett-Sheehan, K., Janavs J., Weiller, E., Bonara, L.I., Keskiner, A., Schinka, J., Knapp, E., Sheehan, M.F., Dunbar, G.C. (1997). Reliability and Validity of the MINI International Neuropsychiatric Interview (M.I.N.I.): According to the SCID-P. European Psychiatry, 12, 232-241.

Stern, D. (1985). El mundo interpersonal del infante. Una perspectiva desde el psicoanálisis y la psicología evolutiva. Buenos Aires: Paidós.

Storfer, M. (1999). Myopia, intelligence, and the expanding human neocortex: Behavioral influences and evolutionary implications. International Journal of Neuroscience, 98, 153-276. doi: 10.3109/00207459908997465

Suárez, N., Muñoz, M., Gómez, E. \& Santelices, M. (2009) Terapia de Interacción Guiada: Una Nueva Modalidad de Intervención con Familias Multiproblemáticas y en Riesgo Social. Terapia Psicológica; 27(2),203-213.

Székely, E., Lucassen, N., Tiemeier, H., BakermansKranenburg, M., Van IJzendoorn, M., Kok, R. \& Herba, C. (2014). Maternal depressive symptoms and sensitivity are related to young children's facial expression recognition: The Generation R Study. Development and Psychopathology, 26, 333-345. doi: 10.1017/S0954579413001028

Trevarthen, C. \& Aitken, K. (2001). Infant intersubjectivity: Research, Theory, and Clinical Applications. Journal of Child Psychology and Psychiatry, 42(1), 3-48. doi : 10.1111/1469-7610.00701

Urdaneta, J., Rivera, A., García, J., Guerra, M., Baabel, N., \& Contreras, A. (2010). Prevalencia de depresión posparto en primigestas y multíparas valoradas por la Escala de Edimburgo. Revista chilena de obstetricia y ginecología, 75(5), 312-320. doi: 10.4067/S0717-75262010000500007

Van Doesum, K., Riksen-Walraven, J. M., Hosman, C. M., \& Hoefnagels, C. (2008). A randomized controlled trial of a home-visiting intervention aimed at preventing relationship problems in depressed mothers and their infants. Child Development, 79(3), 547-561. doi: 10.1111/j.1467- 
8624.2008.01142.x

Van Zeijl, J., Mesman, J., Van IJzendoorn, M. H., BakermansKranenburg, M. J., Juffer, F., Stolk, M. N. \& Alink, L. R. (2006). Attachment-based intervention for enhancing sensitive discipline in mothers of 1-to 3-year-old children at risk for externalizing behavior problems: a randomized controlled trial. Journal of Consulting and Clinical Psychology, 74(6), 994. doi: 10.1037/0022-006X.74.6.994

Vik, K. \& Braten, S. (2009). Video interaction guidance inviting transcendence of postpartum depressed mothers' self-centered state and holding behavior. Infant Mental Health Journal; 30(3):287-300. doi: 10.1002/imhj.20215

Wan, M. W., \& Green, J. (2009). The impact of maternal psychopathology on child-mother attachment. Archives of Women's Mental Health, 12(3), 123-134. doi: 10.1007/s00737-009-0066-5

Yagmur, S., Mesman, J., Malda, M., Bakermans-Kranenburg, M. J., \& Ekmekci, H. (2014). Video-feedback intervention increases sensitive parenting in ethnic minority mothers: a randomized control trial. Attachment \& Human Development, 16(4), 371-386. doi: 10.1080/14616734.2014.912489

ZERO TO THREE (2005). Diagnostic classification of mental health and developmental disorders of infancy and early childhood: Revised edition (DC:0-3R). Washington, DC: ZERO TO THREE Press.

Zietlow, A. L., Schlüter, M. K., Nonnenmacher, N., Müller, M., \& Reck, C. (2014). Maternal Self-confidence Postpartum and at Pre-school Age: The Role of Depression, Anxiety Disorders, Maternal Attachment Insecurity. Maternal and Child Health Journal, 18(8), 1873-1880. doi: 10.1007/s10995-014-1431-1

Submitted: May 2015 Accepted: November 2015 Published: December 2015 